\title{
Expression of B7 (CD80) and CD40 antigens and the CD40 ligand in Hodgkin's disease is independent of latent Epstein-Barr virus infection
}

\author{
P G Murray, J Oates, G M Reynolds, J Crocker, L S Young
}

\begin{abstract}
Aim-To examine the expression of CD40 and B7 (CD80) antigens and the CD40 ligand in Hodgkin's disease. Methods-Antigen and ligand expression was studied in 17 cases of Hodgkin's disease using immunohistochemistry. The study included 11 cases of Hodgkin's disease in which latent Epstein-Barr virus (EBV) infection could be demonstrated within tumour cells by in situ hybridisation for the EBV encoded early RNAs (EBERs). Results-In all cases, irrespective of EBV status, Reed-Sternberg cells and their variants (HRS cells) showed strong expression of both B7 and CD40 antigens. CD40 ligand expression was not shown in HRS cells but was confined to a subset of small lymphocytes some of which were seen to be in intimate contact with HRS cells.

Paraffin wax sections from a further 60 cases of Hodgkin's disease were examined for CD40 and EBER expression alone. The CD40 antigen was identified in HRS cells in all of these cases irrespective of EBER expression.

Conclusions-As CD40 and B7 expression are features of professional antigen presenting cells, these results provide further evidence that HRS cells may have antigen presenting properties and that this may contribute to the characteristic recruitment and activation of non-malignant lymphocytes which is a feature of Hodgkin's disease. The ability of HRS cells to activate $T_{h}$ cells may in turn contribute to their own survival through the induction of the gp39/CD40 pathway.

(f Clin Pathol: Mol Pathol 1995;48:M105-M108)
\end{abstract}

Institute for Cancer Studies, University of Birmingham, Birmingham B15 2TJ

P G Murray

L S Young

Department of Histopathology, Birmingham Heartlands Hospital, Bordesley Green East, Green East, Birming

J Crocker

Department of Pathology, University of Birmingham G M Reynolds

Correspondence to: Professor LS Young.

Accepted for publication 13 January 1995
Keywords: Hodgkin's disease, B7 (CD80) antigen, CD40 antigen, CD40 ligand.

Thymus dependent humoral immune responses require interactions between $B$ cells and CD $4+$ helper $T\left(T_{b}\right)$ cells. Processed antigen is expressed on the surface of antigen presenting $B$ cells in a complex with major histocompatibility complex (MHC) class II molecules and presented for $T_{h}$ cell recognition. Upon recognition of this complex, MHC class II compatible, antigen specific $T_{h}$ cells physically associate with the antigen presenting cell. Ligation of CD4 and the $\mathrm{T}$ cell receptor with the antigen/MHC class II complex, together with the interaction of other surface molecule ligand pair receptors, including CD28-B7 and LFA1-ICAM1, activate the $T_{h}$ cell. Once activated, $T_{h}$ cells rapidly express lymphokine genes and a membrane protein gp39 (CD40 ligand), which is essential for the reciprocal activation of the antigen pre- senting B cell. The interaction of gp 39 with its receptor, $\mathrm{CD} 40$, on the $\mathrm{B}$ cell drives $\mathrm{B}$ cells to enter the cell cycle and induces $B$ cell responsiveness to the growth and differentiating effects of lymphokines. ${ }^{2}$

The origin of the malignant Hodgkin's and Reed-Sternberg (HRS) cells of Hodgkin's disease and their relationship to the reactive cells which characterise the disease have long been the subjects of debate. Phenotyping of HRS cells by immunohistochemistry has suggested many possible cells of origin including follicular dendritic cells, ${ }^{3-5}$ interdigitating reticulum cells, macrophages, ${ }^{6}$ and activated B or T lymphocytes. $^{7}$ Gene rearrangement analysis of Hodgkin's disease has produced conflicting results. Although rearrangement of the immunoglobulin or $T$ cell receptor genes has been shown in some cases, it is not clear whether this is occurring within HRS cells or oligoclonal proliferations of surrounding reactive lymphocytes. ${ }^{89}$

Although the origin of the HRS cell is unclear, the relationship between these cells and the neighbouring non-malignant lymphocytes may be of greater significance if this disease is to be understood. HRS cells are potent stimulators of the mixed lymphocyte reaction and are able to present soluble antigen to $\mathrm{T}$ cells in an MHC restricted fashion. ${ }^{1011}$ They also express ICAM1, LFA3, and MHC class II molecules. ${ }^{12}$ Taken together these findings imply that the HRS cell may be an antigen presenting cell which is able to recruit and activate the surrounding non-malignant lymphocytes. In this study we report the expression of both CD40 and B7 antigens and the CD40 ligand in Hodgkin's disease, providing further evidence of complex and important interactions between these cells and the surrounding lymphocytes.

\section{Methods}

SPECIMENS

Lymph node biopsies from a total of 17 cases of Hodgkin's disease were available as frozen and paraffin embedded tissue samples. A further 60 cases were available only as paraffin embedded specimens. All specimens were obtained from either Birmingham Heartlands Hospital or the Queen Elizabeth Hospital, Birmingham. Haematoxylin and eosin stained sections from each block were reviewed by a single observer and subtyped according to the Rye classification system (table 1).

\section{SECTION PREPARATION}

Frozen sections were cut on a cryostat at $5 \mu \mathrm{m}$, allowed to air dry for 5 minutes, and then fixed for 20 minutes in acetone at $4^{\circ} \mathrm{C}$. Paraffin wax sections were cut at $4 \mu \mathrm{m}$ onto adhesive coated 
Table 1 Expression of Epstein-Barr virus encoded early RNAs (EBERs) and B7 and CD40 antigens within HRS cells of the initial 17 cases of Hodgkin's disease examined

\begin{tabular}{lllll}
\hline Case number & Subtype & EBER & B7 antigen & CD40 antigen \\
\hline 1 & NS & + & + & + \\
2 & NS & + & + & + \\
3 & NS & + & + & + \\
4 & NS & + & + & + \\
5 & NS & + & + & + \\
6 & NS & + & + & + \\
7 & NS & + & + & + \\
8 & MC & + & + & + \\
9 & MC & + & + & + \\
10 & MC & + & + & + \\
11 & LP & + & + & + \\
12 & NS & - & + & + \\
13 & NS & - & + & + \\
14 & NS & - & + & + \\
15 & NS & - & + & + \\
16 & NS & - & + & + \\
17 & LP & - & + & +17 \\
Totals & & $11 / 17$ & $17 / 17$ & + \\
\hline
\end{tabular}

slides (Frotissuer, Binding Site Ltd, Birmingham) and were left at $60^{\circ} \mathrm{C}$ overnight before immunostaining. Sections for EpsteinBarr virus encoded early RNA (EBER) in situ hybridisation were prepared under RNAse-free conditions.

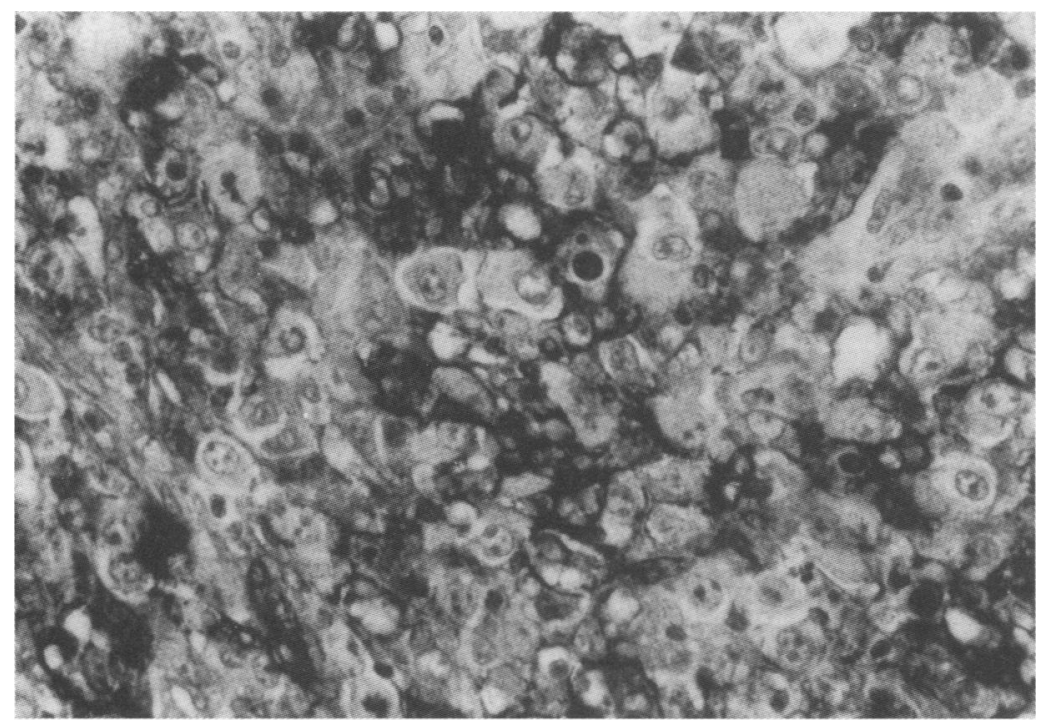

Figure 1 CD40 expression by normal germinal centre $B$ cells and follicular dendritic cells. Paraffin wax section, G28-5 antibody. (Reproduced magnification $\times 245$.)

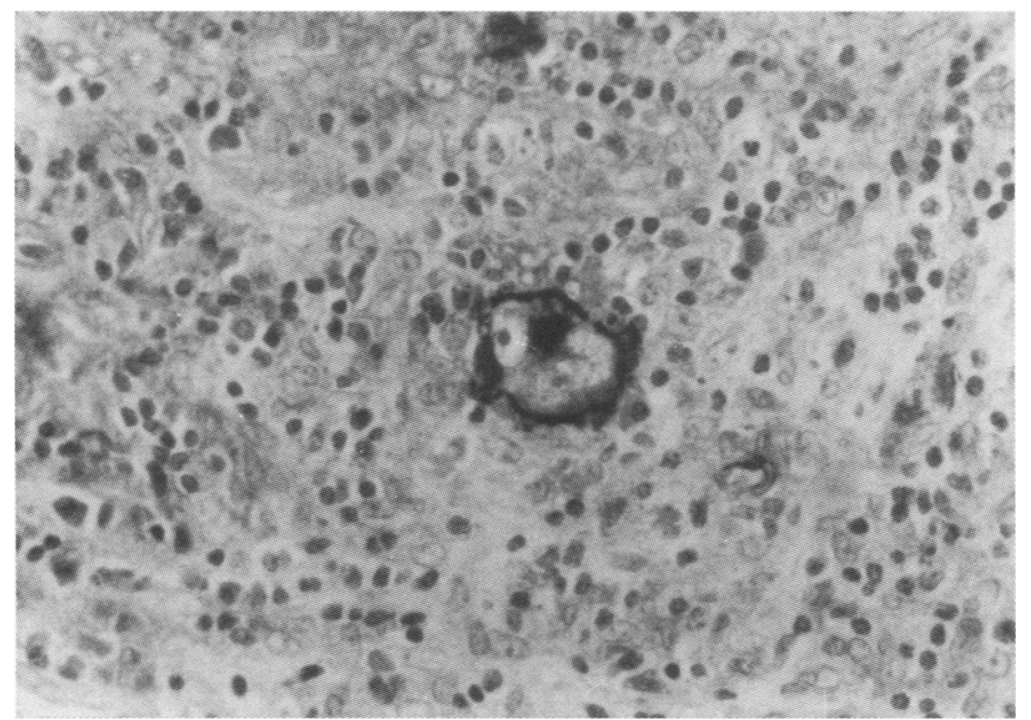

Figure 2 Strong expression of CD40 by a HRS cell in a case of mixed cellularity Hodgkin's disease. Paraffin wax section, G28-5 antibody. (Reproduced magnification $\times 245$.)
EBER IN SITU HYBRIDISATION

EBER in situ hybridisation was employed on both paraffin and frozen sections to identify those cases in which Epstein-Barr virus (EBV) was present within tumour cells. Digoxigenin labelled sense and antisense probes to EBER1 and EBER2 sequences were generated from the plasmids BSJJJ1 and BSJJJ2 and were used as a cocktail in a rapid in situ hybridisation assay as previously described. ${ }^{13}$ Positive controls consisted of a known EBV positive Hodgkin's disease specimen and a lymphoblastoid cell line grown as a tumour in a SCID mouse.

\section{IMMUNOSTAINING}

Paraffin wax sections were deparaffinised and transferred to Tris buffered saline (TBS), $\mathrm{pH}$ $7 \cdot 6$. Frozen sections were transferred directly to TBS.

Two mouse monoclonal antibodies were employed separately on each specimen to identify expression of the CD40 antigen. G28-5 was used at a dilution of $1 / 100$ and S2C-6 at a dilution of $1 / 50$. Both were equally effective in demonstrating CD40 expression in both paraffin wax and frozen sections. Normal tonsil provided a suitable positive control for CD40 expression.

Similarly the mouse monoclonal antibodies dol-1 and BB1 were employed to detect the B7 antigen at dilutions of $1 / 50$ and $1 / 100$ respectively. Both antibodies were effective on frozen sections of control lymphoblastoid SCID tumours and acetone fixed cytospin preparations of the Hodgkin's cell line KMH2. However, paraffin sections yielded only weak signals and B7 expression could therefore not be reliably assessed in paraffin wax tissue sections.

The monoclonal antibodies $\mathrm{M} 90$ and $5 \mathrm{c} 8$ (Immunex) (Dr S Lederman, Columbia University, New York, USA) were employed to detect the CD40 ligand. Both antibodies were used at a dilution of 1/50 and were effective on frozen sections of tonsil specimens. They were not found to be suitable for use on paraffin wax sections.

Selected cases were also analysed for the expression of the EBV encoded latent membrane protein-1 (LMP-1) using the CS1-4 monoclonal antibody preparation at a dilution of $1 / 200$. Microwave pretreatment for $20 \mathrm{~min}$ utes in citrate buffer, $\mathrm{pH} 6.0$, was employed before immunostaining for LMP-1. All primary antibodies were diluted in TBS containing $10 \%$ normal sheep serum.

Bound primary antibodies were detected either by the standard APAAP technique in the case of frozen sections or by a peroxidase based avidin-biotin method for paraffin sections. Negative controls consisted of substitution of the primary antibodies with non-immune serum of the same immunoglobulin subclass.

\section{Results}

EBV was detected by EBER in situ hybridisation in a total of 21 of 77 cases of Hodgkin's disease examined. In all cases the hybridisation signal was confined to the nuclei of HRS cells and in some cases showed the characteristic nucleolar sparing. Expression of LMP-1 in the cytoplasm of HRS cells in EBER 


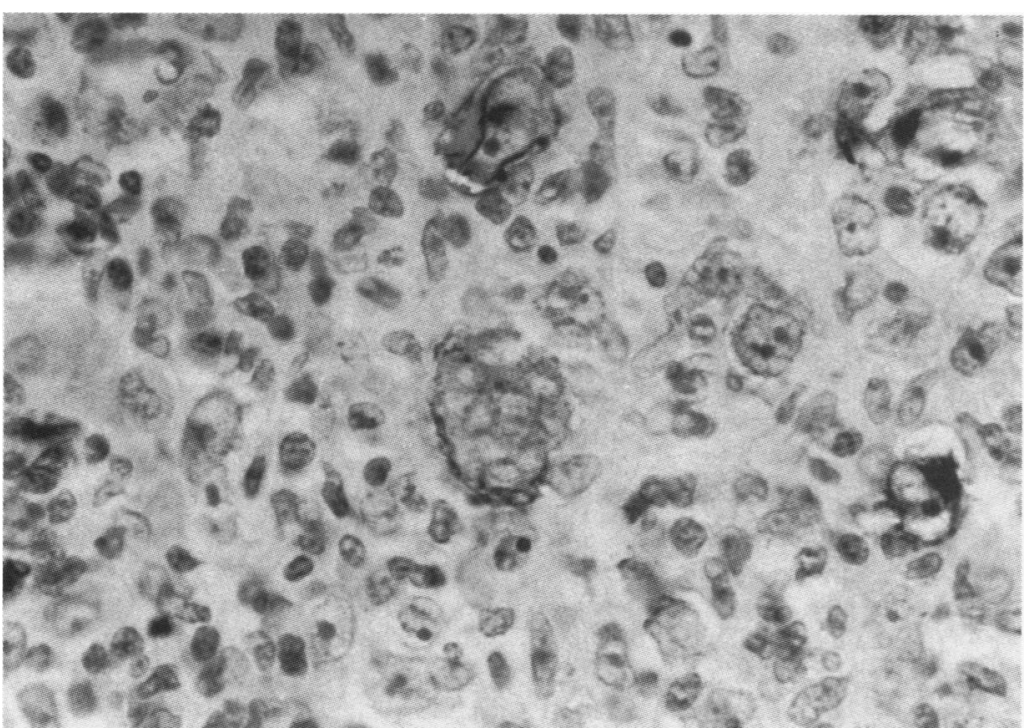

Figure 3 B7 expression within HRS cells in a case of nodular sclerosis Hodgkin's disease. Frozen section, BB1 antibody. (Reproduced magnification $\times 245$.)

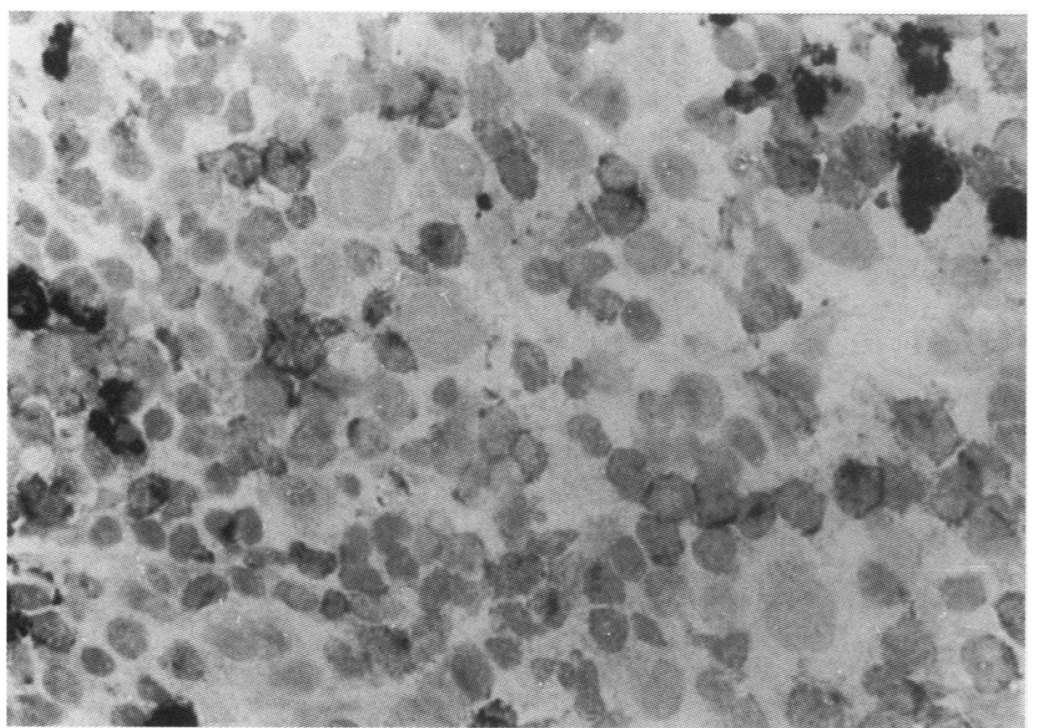

Figure 4 Expression of CD40 ligand on several small lymphocytes surrounding HRS cells. (Reproduced magnification $\times 245$.)

positive specimens was confirmed in all cases. CD40 was shown equally well in both frozen and paraffin tissue and with both monoclonal antibodies. In normal tonsil, germinal centre B cells and follicular dendritic cells showed both membrane and cytoplasmic staining with the CD40 antibodies (fig 1). Occasional interdigitating reticulum cells and immunoblastic cells in interfollicular regions were also stained. In Hodgkin's disease, CD40 was strongly expressed on the membrane and within the cytoplasm of HRS cells in all cases examined irrespective of the presence of latent EBV infection (fig 2). CD40 was also strongly expressed on follicular dendritic cells within

Table 2 Expression of CD40 antigen in HRS cells in paraffin sections from an additional 60 cases of Hodgkin's disease by subtype and Epstein-Barr virus statu

\begin{tabular}{lll}
\hline & \multicolumn{2}{l}{ CD40 expression } \\
\cline { 2 - 3 } Subtype & EBER positive cases & EBER negative cases \\
\hline Nodular sclerosis & $6 / 6$ & $37 / 37$ \\
Mixed cellularity & $1 / 1$ & $3 / 3$ \\
Lymphocyte predominant & $2 / 2$ & $5 / 5$ \\
Lymphocyte depletion & $1 / 1$ & $3 / 3$ \\
Unclassified Hodgkin's disease & $0 / 0$ & $2 / 2$ \\
\hline
\end{tabular}

$\mathrm{EBER}=\mathrm{EB}$ virus encoded early RNA. germinal centres in a few cases of Hodgkin's disease where residual normal lymph node tissue remained.

B7 antigen could only be reliably demonstrated on frozen material. Therefore, only the 17 cases in which frozen biopsy material was available could be assessed for B7 expression. B7 antigen was demonstrated both within the cytoplasm and on the cell membrane of HRS cells in all 17 cases irrespective of the presence of latent EBV infection (fig 3). The EBV negative Hodgkin's cell line $\mathrm{KMH} 2$ also strongly expressed B7. B7 expression could also be demonstrated within infiltrating macrophages found in high numbers in some of the cases of Hodgkin's disease examined. In some Hodgkin's disease specimens some residual normal lymphoid tissue remained. In these cases B7 expression could be shown in B cells and macrophages within normal germinal centres. These results are summarised in tables 1 and 2 .

CD40 ligand expression was performed only on those cases for which frozen sections were available. In all cases CD40 ligand expression was confined to a subset of small lymphocytes some of which were occasionally seeen to be intimately associated with HRS cells (fig 4). However, only a small number of the reactive lymphocytes immediately surrounding HRS cells were CD40 ligand positive in any given case.

\section{Discussion}

In this study we have shown the expression of the B7 antigen (now designated CD80) within HRS cells in all cases of Hodgkin's disease examined, irrespective of subtype or the presence of latent EBV infection within tumour cells. The B7 antigen is expressed on professional antigen presenting cells and is the natural ligand for CD28 on T cells. ${ }^{14}$ Binding of $\mathrm{B} 7$ to $\mathrm{CD} 28$ provides an important costimulatory signal for $T$ cell activation after engagement of the $T$ cell receptor, leading to $T$ cell proliferation and the secretion of cytokines including interleukin-2 (IL-2), tumour necrosis factor $\alpha(\mathrm{TNF} \alpha)$, and $\gamma$ interferon (IFN $\gamma) .{ }^{1516}$ HRS cells express the IL-2 receptor ${ }^{17}$ and their ability to induce IL-2 expression on surrounding lymphocytes might provide a means by which HRS stimulate their own proliferation. HRS cells have also previously been shown to express MHC class II molecules and the adhesion molecules ICAM1 and LFA3, and cells from the Hodgkin's disease cell line L428 are able to present soluble antigen to $\mathrm{T}$ cells in an MHC restricted fashion. ${ }^{11}$ Taken together, these results suggest that HRS cells express a number of the molecules necessary to engage and activate $T_{b}$ cells. An antigen presenting role for the HRS cell might explain the presence of large numbers of nonmalignant cells, including $T$ cells, which are characteristically found in close association with HRS cells in many forms of Hodgkin's disease. Some of these $\mathrm{T}$ lymphocytes have also been shown to express CD28. ${ }^{18}$

Previous studies have reported the expression of $\mathrm{B} 7$ antigen by $\mathrm{HRS}$ cells ${ }^{1819}$ but not in relation to the presence of latent $\mathrm{EBV}$ infection of tumour cells. There is evidence that EBV can induce B7 expression in B lymphocytes and B7 is strongly expressed by lymphoblastoid cell 
lines. ${ }^{20}$ The results of this present study however, suggest that B7 expression within HRS cells is not dependent upon EBV infection.

Once activated, $T_{h}$ cells express several lymphokines and the membrane protein $\mathrm{gp} 39^{1}$ which is necessary for the reciprocal activation of the cognate antigen presenting $B$ cell. The interaction of gp39 with its receptor, CD40, on the B cell stimulates the B cell to enter the cell cycle and induces $B$ cell responsiveness to the growth and differentiating effects of various lymphokines. ${ }^{2}$ The finding of CD40 expression on HRS cells suggests a mechanism whereby the HRS cell activates $T_{h}$ cells, which in turn drive proliferation of the HRS cell by the gp39/ CD40 pathway. Implicit in this argument is that the activated $T$ cells surrounding HRS cells should express gp39. This study has shown that some, but by no means all, of the cells intimately associated with HRS cells express gp39 (CD40 ligand). Activated $T_{h}$ cells have been shown to upregulate $B 7$ expression on normal and leukaemic B cells, and anti-CD40 monoclonal antibodies significantly inhibit this increased expression. ${ }^{21}$ These results suggest that gp39 on activated $T_{h}$ cells may be an important inducer of B7 expression. HRS cell dependency on survival signals from surrounding $T$ lymphocytes might explain the difficulty in establishing in vitro tumour lines from Hodgkin's patients in many cases.

In this study CD40 was expressed in HRS cells irrespective of the presence of latent EBV infection of tumour cells. Latent membrane protein-1 (LMP-1), a protein produced by EBV in some forms of latency, is known to be expressed in EBV associated Hodgkin's disease ${ }^{22}$ and has been shown to upregulate CD40 expression in vitro. ${ }^{23}$ If CD40 expression is upregulated by LMP-1 in EBV infected HRS cells, alternative mechanisms are clearly operative when EBV is absence. It remains to be established whether by acting as antigen presenting cells, HRS cells are able to induce effective cytotoxic $\mathrm{T}$ cell responses against themselves. These responses might in theory be mediated through either CD4 or CD8 positive cytotoxic $T$ cells. This is particularly relevant in cases where EBV infection can be shown within tumour cells. Peptides from LMP-2, for example, have been found to be efficient targets for cytotoxic $T$ cells in some in vitro systems. ${ }^{24}$ Clearly, the survival of EBV-infected HRS cells implies defects either in antigen processing and presentation, or in immune effector mechanisms.

In the past much effort has been expended on identifying the normal counterpart of the HRS cell. Several recent reports have provided new evidence for a follicular dendritic cell origin, ${ }^{35}$ in particular, HRS share many phenotypic markers in common with follicular dendritic cells, including CD21. ${ }^{3}$ The emerging complex interactions between the HRS cell and its surrounding lymphocytes are beginning to explain some of the unique biological features of this unusual malignancy and suggest that an understanding of the function of the HRS cell may be more relevant than the identification of the cell of origin. In the context of EBV-associated Hodgkin's disease, unravelling the nature of immune interactions between the HRS cells and the surrounding non-malignant component may be relevant to the development of rational therapeutic approaches for this disease.

1 Armitage RJ, Fanslow WC, Strockbine L, Sato TA, Clifford $\mathrm{KN}$, Macduff BM, et al. Molecular and biological characterisation of a murine ligand for CD40. Nature 1992;357: 80-2.

2 Spriggs MK, Armitage RJ, Strockbine L, Clifford KN, Macduff BM, Sato TA, et al. Recombinant human CD40 ligand stimulates B cell proliferation and immunoglobulin E secretion. $\mathcal{F} \operatorname{Exp}$ Med 1992;176:1543-50.

3 Delsol G, Meggetto F, Broussset P, Cohen-Knafo E, al Saati $\mathrm{T}$, Rochaix $\mathrm{P}$, et al. Relation of follicular dendritic reticulum cells to Reed-Sternberg cells of Hodgkin's disease with emphasis on the expression of CD21 antigen. Am $\mathcal{F}$ Pathol 1993;142:1729-38.

4 Curran RC, Jones EL. Dendritic cells and B-lymphocytes in Hodgkin's disease. Lancet 1977;ii:349.

5 Soderstrom KO, Rinne R, Hopsu-Havu VK, Jarvinen M, Rinne A. Hodgkin's disease: a malignancy of follicular dendritic cells? Lancet 1994;343:422-3.

6 Kadin ME, Stites DP, Levy R, Warnke R. Exogenous immunoglobulin and the macrophage origin of Reed-Sternberg cells in Hodgkin's disease. N Engl $\mathcal{F}$ Med 1978;299: 1208-14.

7 Stein H, Mason DY, Gerdes J, O'Connor N, Wainscoat J, Pallesen G, et al. The expression of the Hodgkin's disease associated antigen $\mathrm{Ki}-1$ in reactive lymphoid tissue: evidence that Reed-Sternberg cells and histiocytic malignancies are derived from activated lymphoid cells. Blood 1985;66: 848-58.

8 Griessner H, Feller AC, Mak TW, Lennert K. Clonal rearrangements of $\mathrm{T}$ cell receptor and immunoglobulin genes and immunophenotypic antigen expression in different subclasses of Hodgkin's disease. Int f Cancer 1987;40:15760 .

9 Angel CA, Pringle JH, Naylor J, West KP, Lauder I. Analysis of antigen receptor genes in Hodgkin's disease. $\mathcal{F}$ Clin Pathol 1993;46:337-40

10 Fisher RI, Bostick-Bruton F, Suder DN, Scala G, Diehl V. Neoplastic cells obtained from Hodgkin's disease are potent stimulators of human primary mixed lymphocyte cultures. fImmunol 1983;130:2666-770.

11 Fisher RI, Cossman J, Diehl V, Volkman DJ. Antigen presentation by Hodgkin's disease cells. F Immunol 1985; 135: 3568-71.

12 Hsu SM, Hsu PL. Lymphocyte functional antigens stablize agglutination between Reed-Sternberg cells and T cells, but are not responsible for homotypic binding of Hodgkin's Reed-Sternberg cells. Am ₹ Pathol 1990;137:563-74.

13 Barletta JM, Kingma DW, Charache P, Mann RB, Ambinder RF. Rapid in situ hybridization for the diagnosis of latent Epstein-Barr virus infection. Mol Cell Probes 1993;7:105-9.

14 Linsley PS, Clark EA, Ledbetter JA. T-cell antigen CD28 mediates adhesion with B-cells by interacting with activation antigen B7/BB-1. Proc Natl Acad Sci USA 1990; 87:5031-5.

15 Gimmi CD, Freeman GJ, Gribben JG, Sugita K, Freedman AS, Morimoto C, et al. B-cell surface antigen B7 provides a costimulatory signal that induces T-cells to proliferate a costimulatory signal that induces T-cells to proliferate and secrete

16 Thompson CB, Lindsten T, Ledbetter JA, Kunkel SL, Young HA, Emerson SG, et al. CD28 activation pathway regulates the production of multiple T-cell derived lymphokines/cytokines. Proc Natl Acad Sci USA 1989,86:1333-7.

17 Uchiyama T, Broder S, Waldmann TA. A monoclonal antibody $(\mathrm{Tac})$ reactive with activated and functionally mature T-cells. 1. Production of anti-Tac monoclonal antibody and distribution of $\mathrm{Tac}^{(+)}$cells. F Immunol 1981;126: 1398-403.

18 Munro JM, Freeman AS, Aster JC, Gribben JG, Lee NC, Rhynhart $\mathrm{KK}$, et al. In vivo expression of the $\mathrm{B} 7 \mathrm{co}-$ stimulatory molecule by subsets of antion presenting cells and the malignant cells of Hodgkin's disease. Blood 1994; and the ma3-8.

19 Delabie J, Ceuppens JL, Vandenberghe $P$, de Boer $M$, Coorevits L, De Wolf-Peeters C. The B7/BB-1 antigen is expressed by Reed-Sternberg cells of Hodgkin's disease and contributes to the stimulatory capacity of Hodgkin's disease-drived cell lines. Blood 1993;82:2845-52.

20 Yokochi T, Holly RD, Clark EA. B lymphoblast antigen (BB-1) expressed on Epstein-Barr virus activated B-cell blasts, lymphoblastoid cell lines and Burkitt's lymphomas. f Immunol 1982;128:823-7.

21 Ranheim EA, Kipps TJ. Activated T cells induce expression of B7/BB-1 on normal or leukemic B-cells through a

22 Pallesen G, Hamilton-Dutoit SJ, Rowe M, Young LS. Expression of Epstein-Barr virus latent gene products in pression of Epstein-Barr virus latent gene products in
tumour cells of Hodgkin's disease. Lancet 1991;337: tumour

23 Wang F, Gregory C, Sample C, Rowe M, Liebowitz D, Murray $R$, et al. Epstein-Barr virus latent membrane protein (LMP-1) and nuclear proteins 2 and $3 c$ are effectors of phenotypic change in B-lymphocytes: EBNA-2 and LMP-1 cooperatively induce CD23. F Virol 1990;64: 2309-18.

24 Lee SP, Thomas WA, Murray RJ, Khanim F, Kaur S, Young LS, et al. HLA A2.1 restricted cytotoxic T-cells recognising a range of Epstein-Barr virus isolates through a defined epitope in Latent Membrane Protein LMP2. J Virol 1993; 67:7428-35. 